\title{
SHEAR BOND STRENGTH OF DIFFERENT ADHESIVE RESIN CEMENTS TO DENTIN
}

\author{
Diaaeldin Saad Awad*
}

\begin{abstract}
Objective: This study investigated the shear bond strength SBS of different adhesive resin cements [self-adhesive resin cement RelyX Unicem(RXU), adhesive resin cement with self-etch adhesive RelyX Ultimate with Single bond Universal adhesive (RXUT) and adhesive resin cement that utilize etch and rinse technique RelyX ARC with Single bond 2 adhesive (ARC)] to dentin.

Methods: Sixty extracted molars embedded in epoxy resin were prepared by sectioning the buccal surface to expose flat Buccal dentin and were ground with 400 -grit $\mathrm{SiC}$ paper. The samples were divided into 3 groups $(\mathrm{N}=20)$ based on the adhesive resin cements used. Sixty composite discs $3 \mathrm{~mm}$ in diameter Z 350 (3M ESPE)) were constructed \& bonded to the prepared dentin surfaces according to manufacturer instructions. For each group half the samples were thermo-cycled (TC) between $5-55^{\circ} \mathrm{C}$ for 2500 cycles and then all samples were tested using a universal testing machine using chisel blade. The results were statistically analyzed using Mann-Whitney \&Wilcoxon Signed Ranks tests.
\end{abstract}

Results: The mean SBS ( \pm standard deviation) were: $6.95 \pm 1.5 \mathrm{MPa}$ for RXU, 0 for RXU(TC), $22.58 \pm 5.45$ for RXUT, $15.20 \pm 3.98$ for RXUT (TC), 25.9 \pm 5.3 for ARC, and 19.5 \pm 4.3 for ARC(TC). RXU had significant lower bond strength than both RXUT \&ARC $(\mathrm{P}<0.05)$. No significant difference between RXUT \& ARC after thermo-cycling ( $>>0.05)$.

Conclusions: (1) The self-adhesive resin cement (RXU) had significant lower bond strength to dentin than that of RXUT \& ARC. (2) No significant difference was found between the used adhesive resin cements that utilized self-etch adhesive and that utilized etch $\&$ rinse adhesive.

\section{INTRODUCTION}

Interest in all-ceramic restorations has increased in recent years. Ceramic inlays, onlays, veneers, and complete-coverage crowns have gained popularity. These restorations offer superior esthetics compared with metal-ceramic restorations. However, ceramic restorations are very brittle and in most situations need to be bonded to tooth structure with resin or composite cements. At the tooth surface, an adhesive system is used to bond the luting agent to tooth substrate.

* Lecturer of Crown \& Bridge, Department of Fixed Prosthodontics, Faculty of Dentistry, Suez Canal University, Ismailia, Egypt 
Most resin luting agents require that the tooth surface be treated with a dental adhesive prior to luting of the restoration, although some have selfadhesive properties. Currently, bonding to dental substrates is based on three different strategies: 1) etch-and-rinse, 2) self-etch and 3) Self-adhesive approach as possessing the unique properties of self-adherence to the tooth tissue. More recently, a new family of dentin adhesives has been introduced (universal or multi-mode adhesives), which may be used either as etch-and-rinse or as self-etch adhesives. ${ }^{1}$

Self-etching adhesive systems simultaneously condition, demineralize, and infiltrate both the enamel and the dentin. Thus, the risk of over conditioning dentin, which is a common problem with etch \& rinse adhesive, is reduced, lessening the occurrence of inadequate penetration of adhesive monomers and the development of postoperative sensitivity. The dentinal smear layer is dissolved, but not removed, and becomes incorporated into the hybrid adhesive layer, which can affect the hydrolytic stability of the system. Because selfetch adhesive systems do not require a separate acid conditioning step and moist post-rinse control, they are considered simplified adhesive materials and less sensitive than etch and rinse adhesive. ${ }^{2}$

Self-adhesive resin cements without surface pretreatment has been introduced in 2002. The manufacturer purports that the organic matrix consists of multifunctional phosphoric acid methacrylates. The phosphoric acidic methacrylates can react with the basic fillers in the luting cement and the hydroxyapatite of the hard tooth tissue. ${ }^{3}$

Several in vitro studies ${ }^{\mathbf{4 , 5}, \mathbf{6}}$ reported the bond strength of different adhesive systems used in combination to both enamel and dentin. Little information, however, is available in the literature with regard to the bond strength of the complete tooth/indirect restoration complex using different luting gents categorized by their adhesive system.
So, the purpose of this study was to assess the bonding effectiveness of three adhesive luting agents to dentin with different application procedures using a shear bond strength (SBS) test. The null hypothesis tested in this study that:

1. There would be no significant differences in bonding effectiveness between etch-and-rinse, self-etch and self-adhesive luting agents.

2. Thermo-cycling would decrease the shear bond strength.

\section{MATERIALS AND METHODS}

The protocol of this study was approved by the institutional review board at Suez Canal University, Ismalia, Egypt.

\section{Teeth selection \& preparation}

Sixty extracted intact human molars were selected based on the inclusion criteria that there was no evidence of caries, no restorations and a lack of any cracks or fractures in the crown. An approval was taken from the patients to use their extracted teeth in this study. From the time of extraction, these teeth were kept hydrated in distilled water at room temperature.

The extracted molars were embedded in epoxy resin (kemapoxy $150 \mathrm{CMB}$, Egypt) exposing the buccal surface. In order to make a flat dentin surface suitable for the shear test the embedded teeth were wet ground flat on their buccal surface using a trimmer, then the flat surface were polished with $\mathrm{Si}$ carbide papers of different grit ending with 400 grit.

\section{Samples Grouping}

The specimens were randomly divided into three groups ( $\mathrm{N}=20)$ according to the adhesive resin cement used : Group I prepared for application of selfadhesive resin cement RelyX Unicem(3M ESPE, ST Paul, USA), Group II prepared for application of self-etch adhesive universal Single bond (3M ESPE, ST Paul, USA) \& RelyX Ultimate adhesive 
resin cement (3M ESPE, ST Paul, USA), and Group

III prepared for application of etch \& rinse adhesive "Scotch bond etchant 37\%, Single Bond 2" (3M ESPE, ST Paul, USA) and adhesive resin cement RelyX ARC (3M ESPE, ST Paul, USA).

\section{Bonding Procedures} Composite discs Z 350 XT (3M ESPE, ST Paul, $3 \mathrm{~kg}$ load. Figure 1
USA) $3 \mathrm{~mm}$ in diameter were constructed using split Teflon mould with $3 \mathrm{~mm}$ inner diameter. The composite discs were bonded to the prepared dentin surface using specified adhesive cement according to manufacturer instructions (Table 1). A specially constructed device was used during bonding of the samples that allowed application of standardized

TABLE (1) Resin cements and adhesive system tested

\begin{tabular}{|c|c|c|c|}
\hline $\begin{array}{l}\text { Adhesive } \\
\text { system }\end{array}$ & Classification & Components & Bonding procedures \\
\hline $\begin{array}{l}\text { RelyX } \\
\text { Unicem }\end{array}$ & $\begin{array}{l}\text { Self-adhesive } \\
\text { cement }\end{array}$ & $\begin{array}{l}\text { Powder: Glass fillers,silica, calcium } \\
\text { hydroide, self-cured intiators, } \\
\text { pigment, light-cured initiators (filler } \\
\text { load } 72 \% \text { weight, particle size } \\
<9.5 \text { micrometers) } \\
\text { Liquid: methacrylated phosphonic } \\
\text { esters, dimethacrylates, acetate, } \\
\text { stabilizers, self-curedand light-cured } \\
\text { initiators. }\end{array}$ & $\begin{array}{l}\text { - Activate capsule on the activator and then mix it in } \\
\text { mechanical mixer. } \\
\text { - Apply cement through capsule applicator on the } \\
\text { composite disc after application of silane for one } \\
\text { minute. } \\
\text { - Place the bonded sample in the special device apply } \\
3 \mathrm{~kg} \text { load, remove excess and light cure for } 20 \mathrm{~s} \text { for } \\
\text { every side }\end{array}$ \\
\hline $\begin{array}{l}\text { Single bond } \\
\text { Universal }\end{array}$ & \multirow[t]{2}{*}{$\begin{array}{l}\text { Self-etch } \\
\text { adhesive }\end{array}$} & $\begin{array}{l}\text { MDP phosphate monomer, } \\
\text { dimethacrylate resins bis-GMA, } \\
\text { Hema, Polyalkenoic acid copolymer, } \\
\text { filler, ethanol, water, initiators, silane. }\end{array}$ & $\begin{array}{l}\text { - Apply the adhesive gently, massaging the dentine sur- } \\
\text { face for } 20-30 \mathrm{~s} \text {. } \\
\text { - Do not wash. Gently apply a stream of air and light- } \\
\text { cure for } 20 \mathrm{~s}\end{array}$ \\
\hline $\begin{array}{l}\text { RelyX } \\
\text { Ultimate } \\
\text { cement }\end{array}$ & & $\begin{array}{l}\text { Base: Methacrylate monomers, } \\
\text { radiopaque silanated fillers, initiator, } \\
\text { stabilizers, rheological additives } \\
\text { Catalyst: Methacrylate monomers, } \\
\text { radiopaque alkaline fillers, initiator, } \\
\text { stabilizers, pigements, fluorescence } \\
\text { dye, dark cure activator . }\end{array}$ & $\begin{array}{l}\text { - Dispense equal amount of base and catalyst through } \\
\text { clicker syringe. } \\
\text { - Mix cement with spatula and apply it on the com- } \\
\text { posite disc after application of silane for one minute. } \\
\text { - Place the bonded sample in the special device apply } \\
3 \mathrm{~kg} \text { load, remove excess and light cure for } 20 \mathrm{~s} \text { for } \\
\text { every side }\end{array}$ \\
\hline $\begin{array}{l}\text { Scotchbond } \\
\text { Etchant Gel }\end{array}$ & \multirow[t]{3}{*}{$\begin{array}{l}\text { Etch \& rinse } \\
\text { adhesive }\end{array}$} & $\begin{array}{l}32 \% \text { phosphoric acid, } 50-60 \% \text { water, } \\
5-15 \% \text { polyvinyl alcohol }\end{array}$ & $\begin{array}{l}\text { - Etch dentine surface for } 15 \text { seconds. } \\
\text { - Rinse etchant and dry without desiccation }\end{array}$ \\
\hline $\begin{array}{l}\text { Single bond } \\
2 \text { adhesive }\end{array}$ & & $\begin{array}{l}\text { Dimethacrylate resins bis-GMA, } \\
\text { Hema, Polyalkenoic acid copolymer, } \\
\text { filler, ethanol, water, initiators, }\end{array}$ & $\begin{array}{l}\text { - Apply the adhesive gently, massaging the dentine } \\
\text { surface for } 20-30 \mathrm{~s} \\
\text { - Gently apply a stream of air and light-cure for } 20 \mathrm{~s}\end{array}$ \\
\hline $\begin{array}{l}\text { RelyX ARC } \\
\text { cement }\end{array}$ & & $\begin{array}{l}\text { Mixture of bis-GMA and TEGDMA } \\
\text { resins, zirconia and silica fillers. Filler } \\
\text { loading } 67.5 \% \text {, particle size } 1.5 \mu \mathrm{m}, \\
\text { initators. }\end{array}$ & $\begin{array}{l}\text { - Dispense equal amount of base and catalyst through } \\
\text { clicker syringe. } \\
\text { - Mix cement with spatula and apply it on the com- } \\
\text { posite disc after application of silane for one minute. } \\
\text { - Place the bonded sample in the special device apply } \\
3 \mathrm{~kg} \text { load, remove excess and light cure for } 20 \mathrm{~s} \text { for } \\
\text { every side }\end{array}$ \\
\hline
\end{tabular}



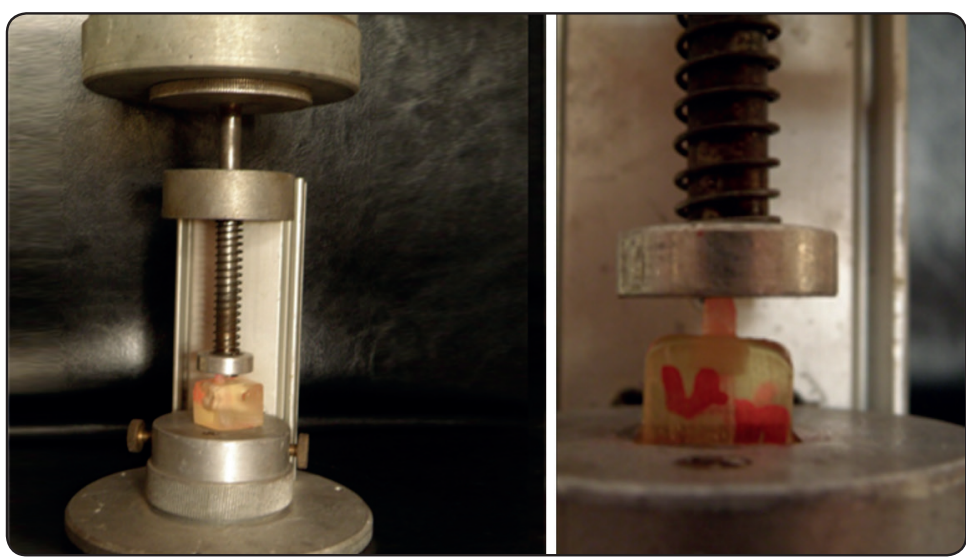

Fig. (1) Specially designed device used during bonding of the samples

\section{Aging, shear bond testing \& analyzing of data}

Half the specimens of each group were thermo-cycled in water bath (MPM Instruments, Bernareggio MI, Italy). The samples were thermoscyled between $5-55^{\circ} \mathrm{C}$ for 2500 cycles, with 10 s dwell time at each bath and transfer time of $5 \mathrm{~s}$, for a total 30s per cycle, before the shear test. A custom made thermo-cyling machine (Faculty of Dentistry Suez Canal University) that allow immersing of the samples in the water baths was used. The shear bond strength was tested using a universal testing machine (Tira GmbH, Schalkau, Germany). Chisel edge blade was used with cross head speed of 0.5 $\mathrm{mm} / \mathrm{min}$. The shear load necessary to debond the specimen was recorded in Newton $(\mathrm{N})$. The shear bond values in Mega Pascal (MPa) were calculated for all tested groups using the following equation:

Shear bond strength in $\mathrm{MPa}=$ Breaking load in $\mathrm{N} /$ bonded surface area in $\mathrm{mm}^{2}$

Bonded area in $\mathrm{mm}^{2}=\pi \mathrm{r}^{2}=3.14 \mathrm{x}(1.5)^{2}=3.14 \mathrm{x}$ $2.25=7.1$

So the value in $\mathrm{M} \mathrm{Pa}=\operatorname{load} \mathrm{N} / 7.1$

The data were analyzed using Mann-Whitney, and Wilcoxon Signed Ranks tests. The overall significance level was set at $(\mathrm{P}$-value $=0.05)$.

\section{RESULTS}

The means and standard deviations of the bond strength are presented in (table 2) and showed in figure 2. Mann Whitney test showed significant difference between each adhesive cement before thermo-cycling at $(\mathrm{P}<0.05)$. After thermo-cycling all the Unicem samples debonded and so no results were recorded. Thermo-cycling led to decrease in the SBS of samples boned with Ultimate and ARC cements. Wilcoxon Signed Ranks tests revealed no significant difference between samples bonded with RelyX Ultimate before and after thermo-cycling. Also no significant difference found between samples bonded with ARC before and after thermocycling. No significant difference was founded between samples bonded with Ultimate and ARC cements after thermos-cycling.

TABLE (2) The mean shear bond strength and SD in (MPa) of the three adhesive resin cements to dentin before and after thermo-cycling.

\begin{tabular}{|c|c|c|c|}
\hline $\begin{array}{c}\text { Cement } \\
\text { Thermo- } \\
\text { cycling }\end{array}$ & $\begin{array}{c}\text { RelayX } \\
\text { Unicem }\end{array}$ & $\begin{array}{c}\text { RelayX } \\
\text { Ultimate }\end{array}$ & $\begin{array}{c}\text { RelayX } \\
\text { ARC }\end{array}$ \\
\hline Before & $6.95 .76 \pm 1.5$ & $22.58 \pm 5.45 *$ & $25.9 \pm 5.3 \#$ \\
\hline After & --------- & $15.2 \pm 3.98 * \S$ & $19.5 \pm 4.3 \# \S$ \\
\hline
\end{tabular}

Results with same symbols have no significant difference

\section{Significant difference at $P<0.05$}

Examination of the failure pattern (Figure 3) showed that the failure mode was $100 \%$ adhesive between cement and dentin in all samples bonded with Unicem cement. For RelyX Ultimate $(40 \%$ adhesive, 60 mixed) and ARC cements (20\% adhesive, $80 \%$ mixed). 


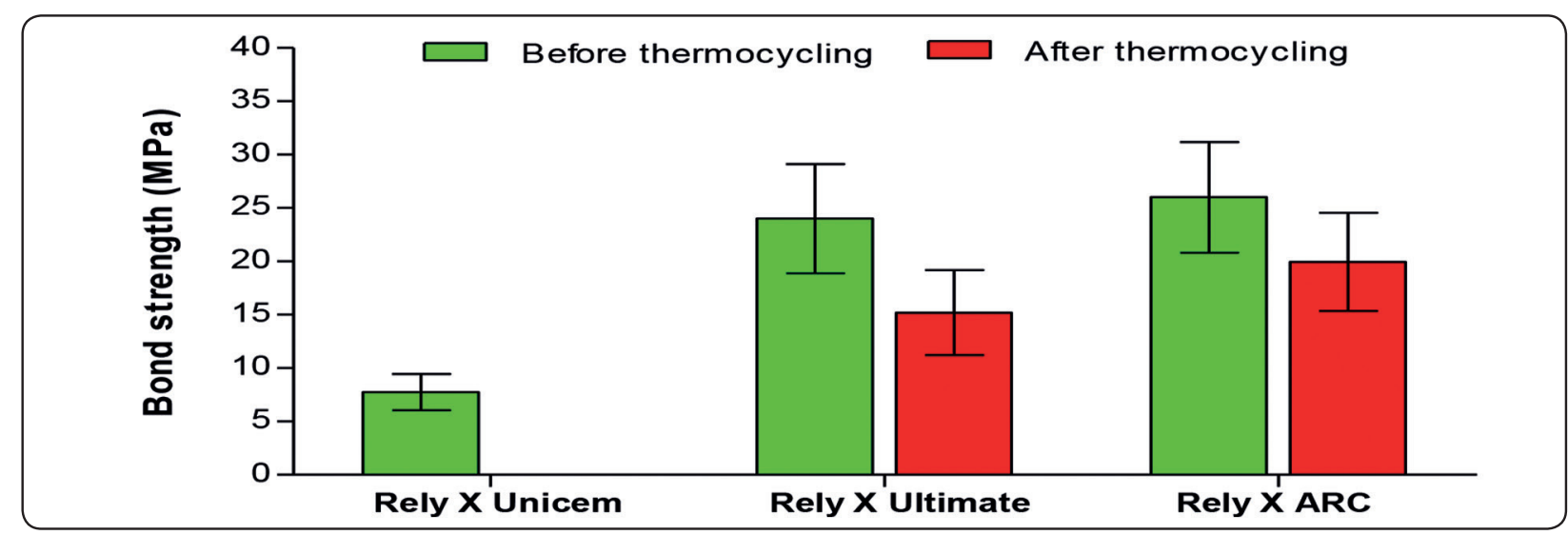

Fig. (2) Shear Bond strength in (MPa) for the three adhesive resin cements to dentin before \& after thermo-cycling

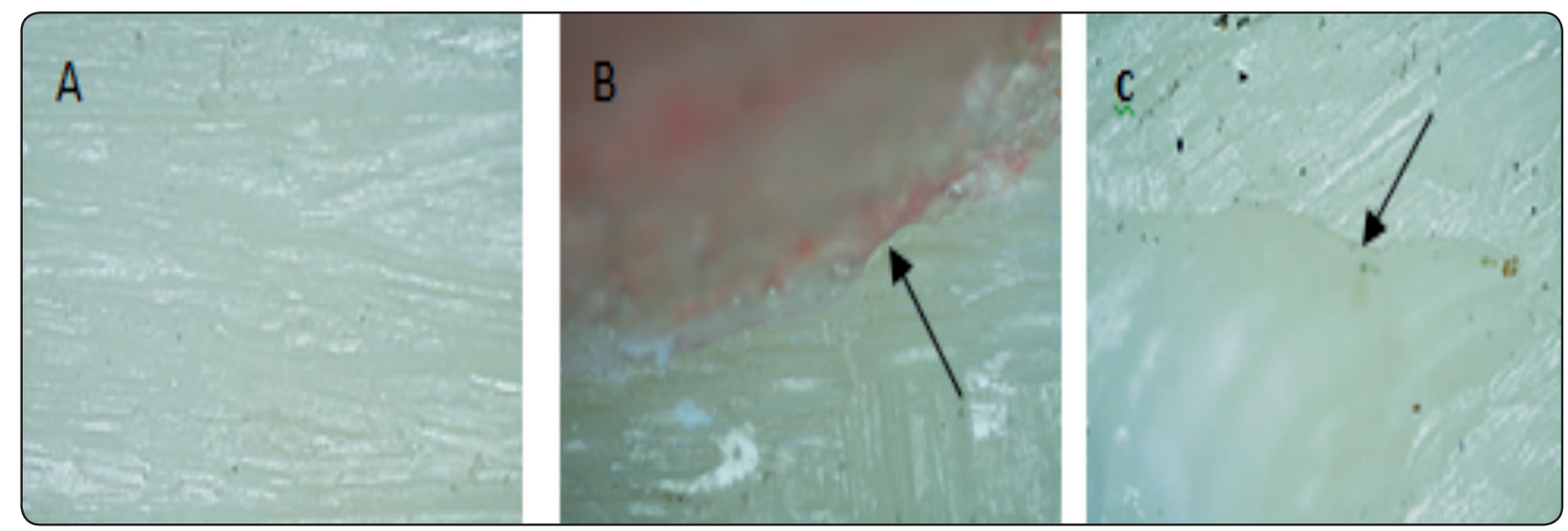

Fig. (3) Failure mode of the three adhesive resin cements A: RelyX Unicem, B: RelyX Ultimate with SBU, C: RelyX ARC with SB2. Arrow shows areas of cement indicating mixed failure pattern (Magnification 20X)

\section{DISCUSSION}

The use of adhesive bonding is widespread throughout clinical dentistry. Each year, manufacturers introduce new bonding systems and new adhesive resin cements making it difficult to be accounted with all these materials. So, it would be sensible to suggest that those who are engaged in research should be able to provide reliable information that would be of assistance to help choosing the proper adhesive material for clinical use.

The evaluation of bond strengths of adhesive cements to tooth substance and restorative materials, either in the tensile or shear mode have been widely reported. Either of these two tests will provide useful information as bonded restorations are subjected to various stresses which exhibit both tensile and shear components.

Aging by thermo-cycling was undertaken in this study to examine the effect of simulated in vivo temperature variations on the strength of the bond at the resin/dentin interface and to test the durability of the bond for the used adhesives. Temperature range within the oral cavity produced by hot or cold drinks were found to be in the range of $5^{\circ}-55^{\circ} \mathrm{C} .{ }^{7}$ This range is well accepted and has been widely applied in studies of the effect of thermo-cycling on bonding to either dental substrate or restorative materials ${ }^{3,4,5}$ 
The ISO TR 11450 standard (1994) indicates that a thermo-cycling regimen of 500 cycles in water between 5 and $55^{\circ} \mathrm{C}$ is an appropriate artificial aging test. Furthermore Thompson, Grolman, and Liao $1985^{8}$ found that the effect of thermal cycling on the bond strength of resin/metal after 10,000 cycles was not significantly different than that after 1000 cycle. Hence, the effect of thermo-cycling can be detected without an excessive number of cycles.

Standardization of the bonded area was achieved by fabrication of composite discs of $3 \mathrm{~mm}$ diameter using split Teflon mold. These composite discs were used in bonding of all samples of the three types of cements. Also standardization of the pressure during bonding was achieved using specially designed device that allowed application of standardized load of $3 \mathrm{Kg}$ for all the samples (figure 1).

The results of this study rejected the null hypothesis for the first statement and accepted for the second. Since the self-adhesive resin cements showed lower bond strength to dentin $(6.95 \mathrm{MPa}$ RelyX Unicem) than that of self-etch (22.58 MPa RelyX Ultimate), and etch \&rinse adhesive resin cement (25.9.1MPa RelyX ARC). After thermocycling the shear bond strength of RelyX Ultimate and RelyX ARC to dentin decreased to (15.2 \& 19.5 $\mathrm{MPa}$ ) respectively.

The difference in the shear bond strength between the self-adhesive resin cements and that of etch and rinse adhesive and self-etch adhesive cement to dentin should be attributed to either the way by which each cement treat and subsequently bond to the dentin or to the chemical composition of each resin cement. Since the three adhesive cements (apart from the incorporated adhesive molecules) have similar chemical composition, so the difference should be attributed to the ability of each cement to treat the dentin surface.

The mechanism of bonding of RelyX ARC depends mainly on micromechanical interlock with partially demineralized dentin with the formation of the hybrid layer. The application of the acid etching agent is reported to remove the smear layer, smear plugs, open the dentinal tubules and demineralize the hydroxyl apatite phase of the dentin surface. ${ }^{9}$ This supposed to open channels around the collagen fibers, these opened channels are supposed to pave the way for the subsequently applied hydrophilic adhesive monomer to form the hybrid layer with dentin. Furthermore, the HEMA which is incorporated in the bonding agent has a bi-functional molecule which is hydrophilic on one side to create a bond with dentin and hydrophobic on the other side to create a bond with the adhesive cement. Adding to that the bonding agent of RelyX ARC have a low viscosity and was applied in a separate bonding step, this might allow it to diffuse easily through the partially demineralized dentin with the subsequently formation of hybrid layer. ${ }^{10}$

Such bonding mechanisms seemed to be good enough to withstand shrinkage stresses induced by polymerization of the resin cements and should be held responsible for creating the bond strength of the RelyX ARC resin cement with etch and rinse adhesive to dentin.

\section{Self-etching adhesives have been developed to:}

1. Simplify bonding procedures.

2. Minimize the technique sensitivity for bonding to tooth structure; 3 . Prevent discrepancies between the depth of dentin demineralization by the acid and the adhesive's ability to penetrate this demineralized layer. ${ }^{2,11}$ One of the basic concepts behind the self-etching adhesive approach is that tooth structure demineralization and bonding agent diffusion and embedding around dentinal collagen fibers happens at the same time and to the same depth. These adhesives systems have been classified into mild, moderate, and aggressive, depending on their PH and ability to solubilize the smear layer and demineralize the underlying subsurface dentin. ${ }^{12}$

According to this classification, Single bond Universal, tested in the present study, classified as a moderate self-etch adhesive system. Such 
adhesive may remain unsatisfactory when used on enamel surfaces. ${ }^{13}$ On dentin this moderate selfetch adhesives might produce higher bond strength which is proved in this study where Single bond Universal produce lower bond strength than etch and rinse adhesive, however the difference where not statistically difference. The good performance of Single bond Universal on dentin could be explained by the ability of this bond to partially dissolve the smear layer and smear plugs and form authentic hybrid layers. ${ }^{1,14}$ Sezinando $2012^{15}$ reported formation of a continuous dentin-resin interface with a $0.2 \mu \mathrm{m}-0.3 \mu \mathrm{m}$ thick hybrid layer when using Single bond Universal on dentin surface in the selfetch mode. Therefore, the bonding mechanism of this self-etching adhesive to dentinal substrate is assumed to be closer to that of total-etch systems, with regard to hybridization and resin tag formation. This means that practically all the mineral content is removed from the collagen network, avoiding any interaction between hydroxyapatite and functional monomers. ${ }^{16}$ The results of this study come in consistence with this explanation and to other studies, ${ }^{17,} 18$ that showed that Adper Scotchbond (etch \& rinse) showed higher bond strength values than Adper Easy One (mild self-etch); however, the difference was not statistically significant.

On the other hand the mechanism of bonding of the self-adhesive resin cements is reported to be dependable on the incorporated adhesive acidic monomers which is claimed to only infiltrate the smear layer without removing the smear plugs. So one can assume that this might lead to create a very thin or even no hybrid layer at all. Furthermore, the acidic monomer and adhesive molecules were all incorporated in the cement and were applied in a one single step. So this could create highly viscous cement ${ }^{19}$ that could limit the penetration ability of the cement through the dentin (In contrast to selfetch and etch \& rinse adhesive cement in which a low viscous bonding agent that were applied separately to dentin).
The previously discussed assumption (very thin or absence of hybrid layer with self-adhesive cement) was well supported in several Scanning Electron Microscope (SEM) studies by Yang B et al $2006,{ }^{18}$ De Munck et al 2004, ${ }^{20}$ Behr et al $2004^{21}$, in which they reported that there was no formation of hybrid layer at the resin dentin interface when selfadhesive resin cements were used.

Since, the hybrid layer might not exist or be very thin, so bonding of the self-adhesive cements might be confined to the smear layer and subsequently the strength of the bond should be limited to the bond strength of the smear layer to dentin. This might explain the relatively lower shear bond strength of the self-adhesive resin cements RelyX Unicem to dentin.

Thermo-cycling as an aging factor used in this study resulted in debonding all the samples bonded with the self-adhesive resin cement. This effect could be attributed to the difference in the coefficient of thermal expansion between the bonded materials at the bonded interface. This difference might lead to higher thermal contraction/ expansion stresses to be generated at the dentin/adhesive cement interface. Hence these stresses might lead to cracks that propagate along the bonded interfaces, and once a gap is created, changing gap dimensions can cause in-and outflow of oral fluids, a process which is known as "percolation"22

The above assumption of the bonding performance of each adhesive agent was augmented by examination of the failure patterns using metallurgical microscope. It showed $100 \%$ adhesive failure at the cement/dentin interface with RelyX Unicem, while with RelyX Ultimate(self-etch) and RelyX ARC (etch and rinse) cohesive failure within the cement itself was shown in addition to adhesive failure at cement/dentin interface. This might be due to the bonding mechanism of self-adhesive resin cements which might have a limited bond to dentin as previously discussed. 


\section{CONCLUSION}

Under the condition of this study the following could be concluded:

1. The tested etch \& rinse agent provided the best overall bonding performance.

2. Both the tested total etch agent and self-etch agents produce a durable bond with dentine while the self-adhesive agent produce the lowest and unreliable bond.

\section{Clinical implication}

1. Both etch \& rinse and self-etch agents could be used safely with restoration that depend mainly on bonding (veneers, resin bonded bridges, short preparation), while self-adhesive cements are not a good choice.

2. Although the low bond strength of self-adhesive resin cements, clinicians could benefit from the low solubility and high mechanical properties of the self-adhesive resin cements for cementation of restorations on preparation that have good retention and resistance.

\section{Limitation of the study}

There is a limitation of the study that it is used only one cement from each category (etch\& rinse, self-etch, self-adhesive) from one manufacturer. Other cements from different manufacturers should be included in future studies. Also as per our assessment scanning electron microscopy and conofocal laser scanning microscopy rather than stereomicroscopy would yield more authentications in examining the failure modes.

\section{REFERENCES}

1. Sofan E, Sofan E, Palaia G, Tenore G, Romeo U, Migliau G. Classification review of dental adhesive systems: from the IV generation to the universal type. Annali di Stomatologia 2017;8 (1):1-17

2. Giannini M, Makishi P, Ayres A, Vermelho PM, Fronza BM, Nikaido T, Tagami J. Self-Etch Adhesive Systems: A Literature Review Brazilian Dental Journal 2015; 26 (1): $3-10$
3. Hikita K, Van Meerbeek B, De Munck J, Ikeda T, Van Landuyt K, Maidab T, Lambrechts P, Peumans M. Bonding effectiveness of adhesive luting agents to enamel and dentin. Dent Mater 2007;23:71-80.

4. Abo-Hamar SE,Hiller KA, Jung H, Federlin M, Friedl KH, Schmalz G: Bond strength of a new universal self-adhesive resin luting cement to dentin and enamel. Clinc Oral Investig 2005;9:161-7.

5. Piwowarczyk A, Bender R, Ottl P, Lauer HC: Long-term bond between dual polymerizing cementing agents and human hard dental tissue. Dent Mater 2007;23:211-7.

6. Holderegger C, Sailer I, Schuhmacher C, Schläpfer R, Hämmerle C, Fischer J: Shear bond strength of resin cements to human dentin. Dent Mater 2008;24:944-50.

7. Longman CM and Pearson GJ: Variation in temperature of the oral cavity during inhibition of hot and cold fluids. (Abstr). J Dent Res 1984;63:521

8. Thompson VP, Grolman KM, and Liao R: Bonding of adhesive resins to various non-precious alloys. J. Dent Res 1985; 64:314 (Abstr.)

9. Vargas MA, Cobb DS, Armstrong SR: Resin-dentin shear bond strength and interfacial ultrastructure with and without a hybrid layer. Oper Dent 1997;22:159-66.

10. Nakabayashi N, Pashely DH: Hybridization of dental hard tissue. Tokyo: Quintessence; 1998. P.16-89.

11. Haller B. Recent developments in dentin bonding. Am J Dent. 2000;13:44-50.

12. Tay FR, Pashley DH. Aggressiveness of contemporary self-etching systems. I: Depth of penetration beyond dentin smear layers. Dent Mater. 2001;17:296-308.

13. Van Meerbeek B, Yoshihara K, Yoshida Y, Mine A, De Munck J, Van Landuyt KL. State of art of self-etch adhesives. Dent Mater 2011;27:17-28.

14. Gupta A, Tavane P, Gupta PK, Tejolatha B, Lakhani AL, Tiwari R, Kashyap S, Garg G. Evaluation of Microleakage with Total Etch, Self Etch and Universal Adhesive Systems in Class V Restorations: An In vitro Study. J of Clinic.and Diagn. R. 2017; 11(4): 53-6.

15. Shinohara MS. Pre-etching Dentin Effects on Bond Strength of Adhesives. (abstract) J Dent Res 2012; 85(B) 1659.

16. Van Meerbeek B, Vargas M, Inoue S. Adhesives and cements to promote preservation dentistry. Oper Dent. 2001;6:119-144 
17. Söderholm KM, Soares F, Argumosa M, Loveland C, Bimsteim E, Guelmann M. Shear bond strength of one etchand-rinse and five self-etching dental adhesives when used by six operators. Acta Odontol Scan 2008:66;243-9.

18. Rabosa CC., Santana IL. Shear bond strength of self-etch and total-etch adhesives to bovine enamel and dentin. Rev Odonto Cienc 2012;27(2):143-146

19. Yang B, Ludwig K, Adelung R, Kern M: Micro-tensile bond strength of three luting resins to human regional dentin. Dent Mater 2006;22:45-56.
20. De Munk J, Vargas M, Van Landuyt K, Hikita K, Lambrechts P, Van Meerbeek B: Bonding of an auto-adhesive luting material to enamel and dentin. Dent Mater 2004;20:963-71.

21. Behr M, Rosentritt M, Regnet T, Lang R, Handel G: Marginal adaptation in dentin of a self-adhesive universal resin cement compard with well-tried systems. Dent Mater 2004; 20:191-7.

22. Gale MS, Darvell BW: Thermal cycling procedures for laboratory testing of dental restorations. J Dent 1999; 27:89-99. 